Article

\title{
Experimental Study of $n$-Decane Decomposition with Microsecond Pulsed Discharge Plasma
}

\author{
Feilong Song ${ }^{1}$, Di Jin ${ }^{1}$, Min Jia ${ }^{1}$, Wenwen Wei ${ }^{2}$, Huimin Song ${ }^{1}$ and Yun Wu ${ }^{1,3, *}$ \\ 1 Science and Technology on Plasma Dynamics Laboratory, Airforce Engineering University, Xi'an 710038, \\ China; 18789430752@163.com (F.S.); james.jd@163.com (D.J.); duoduo111134@sohu.com (M.J.); \\ min_cargi@sina.com (H.S.) \\ 2 State Key Laboratory of Multiphase Flow in Power Engineering, Xi'an Jiaotong University, Xi'an 710049, \\ China; weiwww@mail.xjtu.edu.cn (W.W.) \\ 3 Science and Technology on Plasma Dynamics Laboratory, Xi'an Jiaotong University, Xi' an 710049, China; \\ * Correspondence: wuyun1223@126.com; Tel.: +0086-29-8478-7527
}

\begin{abstract}
A highly-integrated experimental system for plasma decomposition of fuels was built. Experiments were conducted and confirmed that macromolecular chain hydrocarbons were cracked by large-gap dielectric barrier discharge under the excitation of a microsecond-pulse power supply. Alkanes and olefins with a $C$ atom number smaller than 10 as well as hydrogen were found in the cracked products of $\mathrm{n}$-decane $\left(n-\mathrm{C}_{10} \mathrm{H}_{22}\right)$. The combination of preheating and plasma decomposition had strong selectivity for olefins. Under strong discharge conditions, micromolecular olefins were found in the products. Moreover, there was a general tendency that micromolecular olefins gradually accounted for higher percentage of products at higher temperature and discharge frequency.
\end{abstract}

Keywords: Plasma; DBD; decomposition; $n$-decane

\section{Introduction}

The continuous rotating detonation engine (CRDE) has tremendous potential for improving the performances of aero-propellers [1-3]. However, initiating the CRDE and the propagation of the detonation wave are extremely sensitive to the activity of the combustible mixture. Currently, gas fuels such as hydrogen, acetylene, and methane can be initiated using air as the oxidant, during which the produced detonation wave can last for a certain time. For liquid fuels such as gasoline, diesel, and kerosene, the denotation can be initiated by supplying oxygen or by using oxygen as the oxidant [4]. Transforming macromolecular hydrocarbons in liquid fuels, such as kerosene, into micromolecular hydrocarbons that are more prone to detonate has proven to be an effective way of using CRDE in current aircrafts. Cheng et al. proposed that olefins exceeded alkanes in laminar combustion rates, and further, the laminar combustion rates of straight-chain olefins were greater than those of branched-chain olefins [5]. Additionally, olefins have better combustion performances than alkanes at low temperatures [6]. These conclusions show direct significance of further cracking experiments from the aspect of cracked product categories.

At present, traditional cracking methods include thermal cracking [7-8] and catalytic cracking [9]. Thermal cracking requires high temperature. For example, the initial cracking temperature of ndecane is approximately $900 \mathrm{~K}$ [8]. Catalytic cracking requires expensive catalysts [10] and always brings about catalyst poisoning [11]. By contrast, using plasma technology produces various types of high-energy particles, such as excited particles and free radicals that can theoretically react with macromolecular chain hydrocarbons for decomposition. Moreover, the chemical reaction rate can be greatly increased, and the energy consumption of the reaction can be effectively reduced [12]. Therefore, this novel method of fuel molecules decomposition using plasma has received much attention. Wang et al. [13] used synchrotron vacuum ultraviolet (VUV) ionization mass spectrometry and detected the decomposition products of iso-propyl alcohol under the action of plasma and found 
a great number of free radials and reactive intermediates. Yao et al. [14] processed $n-\mathrm{C}_{10} \mathrm{H}_{22}$ using coaxial dielectric-barrier discharge (DBD) with a discharge gap of $2.6 \mathrm{~mm}$ and micromolecular hydrocarbons were detected in the products. Prieto et al. [15] adopted a parallel-plate electrode for processing static heavy oils and detected a great amount of hydrogen as a result of long retention time. Yu et al. [16] used Ar plasma to process heavy oils and produced a lot of gaseous hydrocarbons including hydrogen, methane, and ethylene, of which a large proportion was methane. Tsolas et al. [17] conducted both pyrolysis and plasma decomposition on $\mathrm{C}_{1}-\mathrm{C}_{4}$ alkanes and heptane, which shows that plasma decomposition remarkably reduced the initial decomposition temperature. However, they did not focus on the decomposition of macromolecular chain hydrocarbons.

To more closely approximate practical engineering applications, the parallel-plate DBD with a discharge gap of $6 \mathrm{~mm}$ was used in this study. $\mathrm{N}$-decane is an important component in aviation kerosene and is generally used in monocomponent or multi-component alternative fuels [18-20]. Thus, in this study we performed plasma decomposition of $\mathrm{n}-\mathrm{C}_{10} \mathrm{H}_{22}$ to examine the combined decomposition of preheating and plasma on the selection of products.

\section{Experimental}

Fig. 1 illustrates the set-up of the experimental system, which consisted of a gas generator, a power supply, an electrical characteristics testing part, and a plasma cracking reactor. Using a digital peristaltic pump (BT300 M) equipped with a 10-roller pump head, n-decane (with a purity of $99 \%$, Huaxia, Chengdu, China) was directed into the vaporizing chamber via a drainage pin. During drainage, the vaporizing chamber remained at $200^{\circ} \mathrm{C}$, the flow rate was $0.174 \mathrm{~mL} / \mathrm{min}$ (which was equivalent to $20 \mathrm{sccm}$ in the gas phase standard state), and the flow error was smaller than $0.5 \%$. Ar (with a purity of $99.999 \%$ ) was blown into the chamber using a mass flow controller (DSN-MFC-400A) with a precision of $1 \%$, and the flow was set as $980 \mathrm{sccm}$. Ar was adequately mixed with the vaporized $\mathrm{n}$-decane in a vaporizing chamber with a volume up to $800 \mathrm{~mL}$. The quartz tube was $380 \mathrm{~mm}$ long. The cracker was placed at the center of the tube furnace, which was $230 \mathrm{~mm}$ long. The heating length was $150 \mathrm{~mm}$, and the temperature was adjustable within the range from room temperature to 1200 $\mathrm{K}$. The other parts of the quartz tube remained at $200^{\circ} \mathrm{C}$. Before discharge, the temperature at the center of the cracker was measured by an axially-movable K-type sheathed thermocouple for which the outer diameter of the sheathed wire was $1.5 \mathrm{~mm}$. This temperature was then adopted as the experimental temperature.

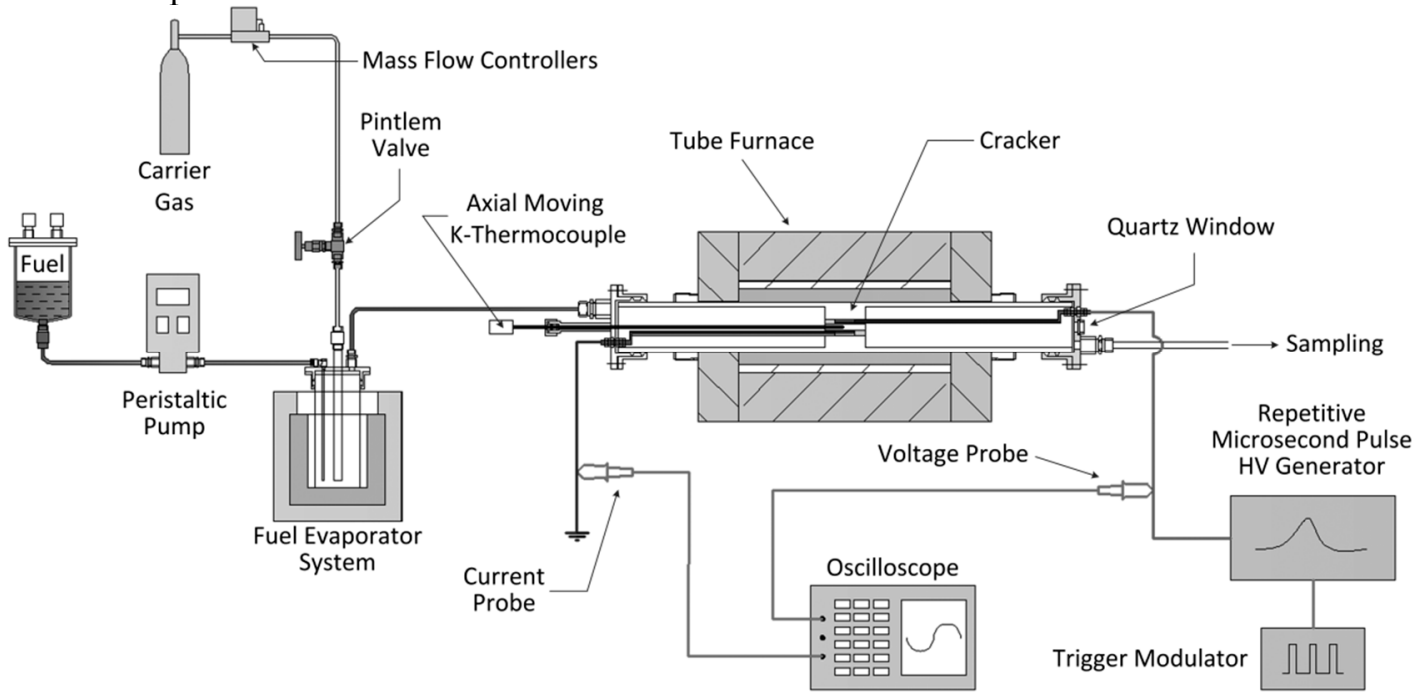

Fig. 1 The schematic diagram of the experimental system.

Fig. 2 shows the structure of the cracker. The plasma was produced using a parallel-plate DBD. Two quartz shells were fastened with four bolts, and the ceramic dielectric layer $(30 \mathrm{~mm}$ long, $30 \mathrm{~mm}$ wide, and $1 \mathrm{~mm}$ thick) was pressed against the top and bottom surfaces of the square quartz tube (1 $\mathrm{mm}$ wall thickness, $6 \mathrm{~mm}$ internal height, and $10 \mathrm{~mm}$ internal width) to produce a uniform plasma discharge and to avoid generating an electric arc. The copper electrode plates $(20 \mathrm{~mm}$ long and 10 mm wide) were placed outside the dielectric layers. M3 threaded holes were drilled at the center of 
each quartz shell, and then the copper electrode plates were pressed against the ceramic surface using copper screws. Two copper screws were connected to a high-voltage power supply and to ground terminals with a copper screw rod. The external width of the square quartz tube was $30 \mathrm{~mm}$, and this effectively prevented creepage between the two electrodes outside of the quartz tube. The volume of the plasma produced by the cracker was $1200 \mathrm{~mm}^{3}$, and the gas was retained for $72 \mathrm{~ms}$.

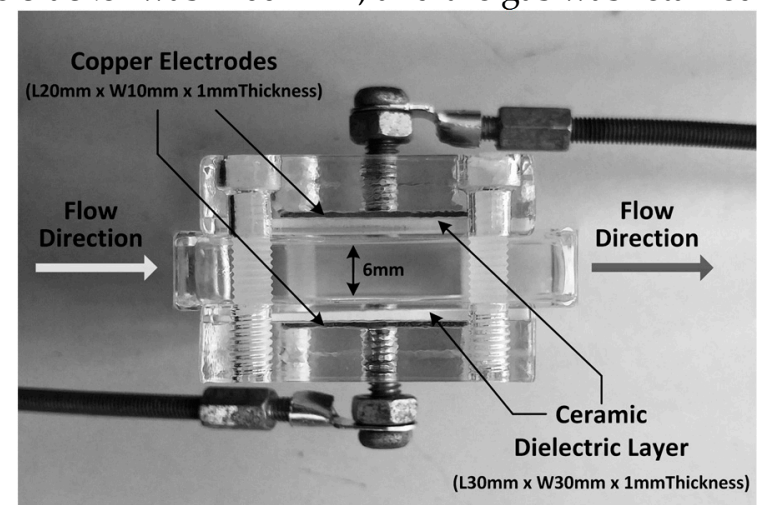

Fig. 2 Picture of the DBD cracker.

The cracker was supplied by a microsecond-pulse power supply. Fig. 3 illustrates the typical voltage-current waveforms. The frequency of the microsecond-pulse power supply was adjustable within the range of $200 \mathrm{~Hz}$ to $5 \mathrm{kHz}$, and the voltage was adjustable from 0 to $12 \mathrm{kV}$ with a rise time of $1.5 \mu \mathrm{s}$. The discharge frequency was precisely controlled via external triggering. The discharge parameters were measured using a high-voltage probe (P6015A) and a current probe (TCP0030A). The data were acquired using a digital oscilloscope (MDO3024).
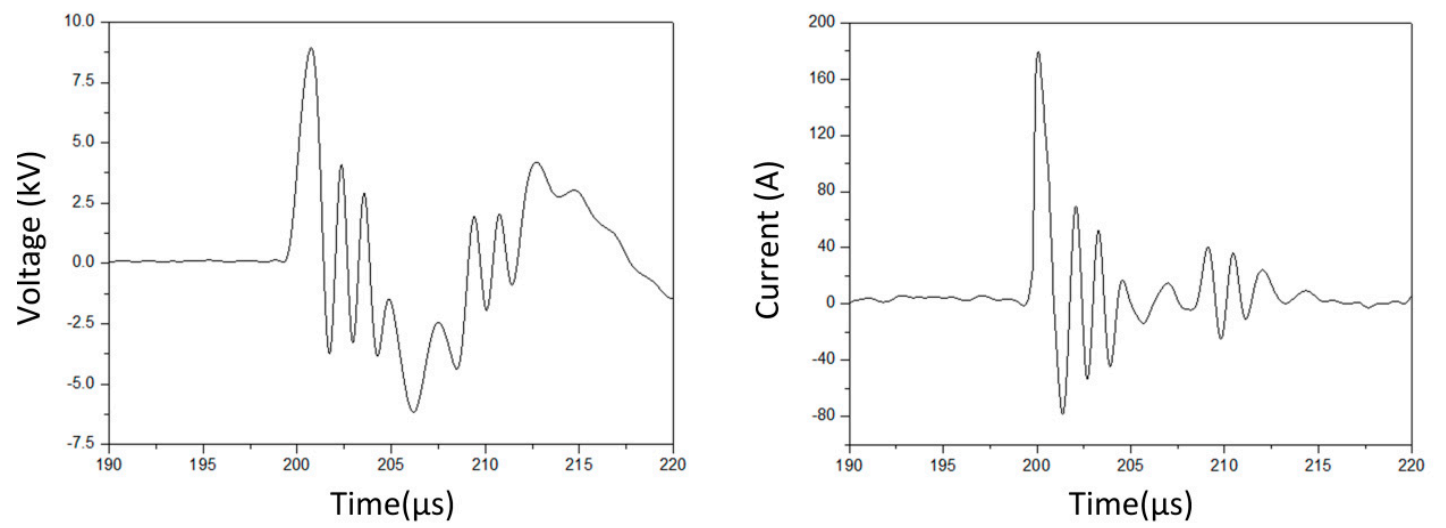

Fig. 3 Typical voltage-current waveforms during discharge.

The experiments were conducted at three temperatures: $520 \mathrm{~K}, 640 \mathrm{~K}$, and $750 \mathrm{~K}$. At each temperature, the discharge frequency was set at $1 \mathrm{kHz}$ and $2 \mathrm{kHz}$, and the discharge voltage was set at $11 \mathrm{kV}$. For comparison, a set of experiments were conducted with a temperature of $823 \mathrm{~K}$ and and frequency of $5 \mathrm{kHz}$. Because of the characteristics of the power supply, the voltage was $9 \mathrm{kV}$.

After air cooling, some high-temperature products from the outlet of the tube furnace condensed into liquids, and others underwent water cooling to collect the gaseous products. $1.8 \mu \mathrm{L}$ of the liquid products were selected and injected into the instrument using a sample injection pin for component analysis. The component detector (GC/MS) included a gas chromatograph (Agilent 6890-series) and mass spectrometer (HP5973N). We acquired qualitative results using the NIST mass spectrometry database. In addition, semi-quantitive analysis was performed on a single component according to the area percentage of the total ion chromatogram in the mass spectra. $100 \mu \mathrm{L}$ of gaseous products were taken and injected into the gas chromatograph (GC) using a sample injection pin. The GC (Agilent 7890) was equipped with a molecular-sieve capillary chromatography column (PLOTC-2000, with a size of $25 \mathrm{~m}^{*} 530 \mu \mathrm{m}^{*} 20 \mu \mathrm{m}$ ) and a thermal conductivity detector (TCD). $\mathrm{H}_{2}, \mathrm{CH}_{4}, \mathrm{C}_{2} \mathrm{H}_{4}$, and $\mathrm{C}_{2} \mathrm{H}_{6}$ were successfully separated. The generated gases were quantitatively analyzed using an external standard method. 


\section{Results and discussion}

Fig. 4 shows the microsecond pulse discharges with and without the injection of $n-\mathrm{C}_{10} \mathrm{H}_{22}$ (a kind of macromolecular straight chain alkane). After the injection of $\mathrm{n}-\mathrm{C}_{10} \mathrm{H}_{22}$, the discharge weakened compared to that after the injection of pure Ar. During the plasma decomposition process, highenergy electrons collided with Ar atoms in each pulse discharge breakdown, and then the Ar atoms were excited from their ground state to a metastable state. Subsequently, the metastable-state Ar atoms collided with molecules or free radials in the carrier gas to crack the molecules and free radials [21-22]. Tsolas et al. [23] conducted related experiments and concluded that, under a high degree of dilution, decomposition induced by the direct collision between elections and molecules contributed slightly to the consumption of the molecules. In this study, the degree of dilution of $n-\mathrm{C}_{10} \mathrm{H}_{22}$ was quite high in the carrier gas with a mole fraction of 0.02 under standard state. The direct collision with electrons hardly cracked $\mathrm{n}-\mathrm{C}_{10} \mathrm{H}_{22}$, and the collisions with metastable-state Ar atoms dominated the decomposition of $\mathrm{n}-\mathrm{C}_{10} \mathrm{H}_{22}$.

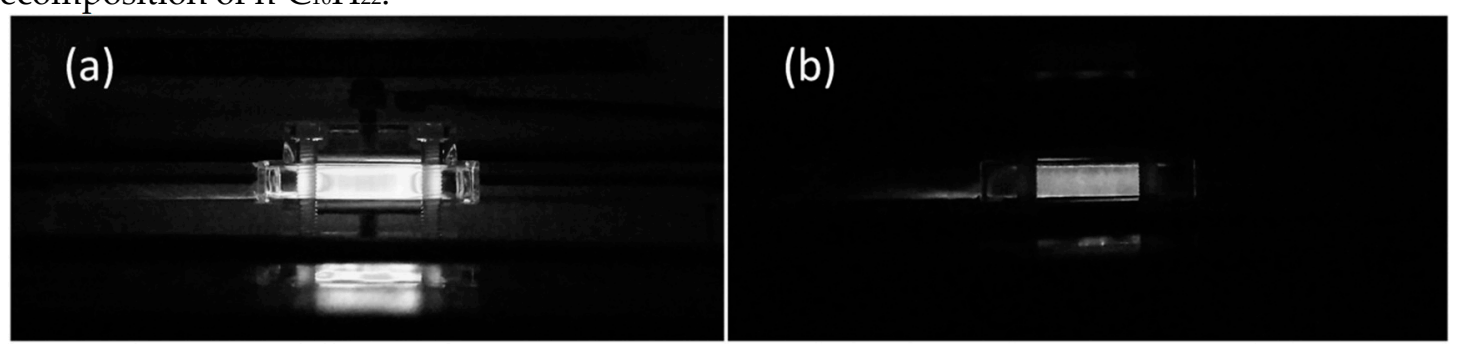

Fig. 4 Illustration of discharge from the DBD cracker. (a) Ar was injected at a rate of 1 SLM. (b) Ar was injected at a rate of $980 \mathrm{sccm}$, and $\mathrm{n}-\mathrm{C}_{10} \mathrm{H}_{22}$ was injected at a rate of $0.174 \mathrm{~mL} / \mathrm{min}$.

Fig. 5 shows the results of the liquid products after the plasma decomposition of $n-\mathrm{C}_{10} \mathrm{H}_{22}$. Ar was used as the carrier gas in the decomposition process. The structure distribution of the detected products under different experimental conditions are given in Table 1. $\mathrm{C}_{6} \mathrm{H}_{12}, \mathrm{C}_{6} \mathrm{H}_{14}, \mathrm{C}_{7} \mathrm{H}_{14}, \mathrm{C}_{7} \mathrm{H}_{16}$, $\mathrm{C}_{8} \mathrm{H}_{16}, \mathrm{C}_{8} \mathrm{H}_{18}, \mathrm{C}_{9} \mathrm{H}_{18}$, and $\mathrm{C}_{9} \mathrm{H}_{20}$ were all found in the liquid products after the decomposition of $\mathrm{n}$ $\mathrm{C}_{10} \mathrm{H}_{22}$ at $520 \mathrm{~K}, 640 \mathrm{~K}$, and $750 \mathrm{~K}$. Zeng et al. [8] carried out pyrilysis experiments on $\mathrm{n}-\mathrm{C}_{10} \mathrm{H}_{22}$ using a flow reactor at normal and low pressures, and Malewicki et al. [24] performed pyrolysis experiments on $\mathrm{n}-\mathrm{C}_{10} \mathrm{H}_{22}$ using a high-pressure shock tube. According to their results, the initial pyrolysis temperature of $n-\mathrm{C}_{10} \mathrm{H}_{22}$ was approximately $900 \mathrm{~K}$, and this suggests that the decomposition products detected in this study were produced in a plasma reaction rather than in a thermal reaction. Since there is only one $\mathrm{nC}_{5} \mathrm{H}_{11}-\mathrm{nC}_{5} \mathrm{H}_{11}$ bond in the $\mathrm{n}-\mathrm{C}_{10} \mathrm{H}_{22}$ molecule, few pentyls were produced, and neither pentane nor pentene were detected in the products as indicated in Table 1. Different free radials recombined and led to the formation of isomers of some products. Moreover, the branched chains of the isomers produced in the plasma decomposition process were mainly methyls and ethyls.

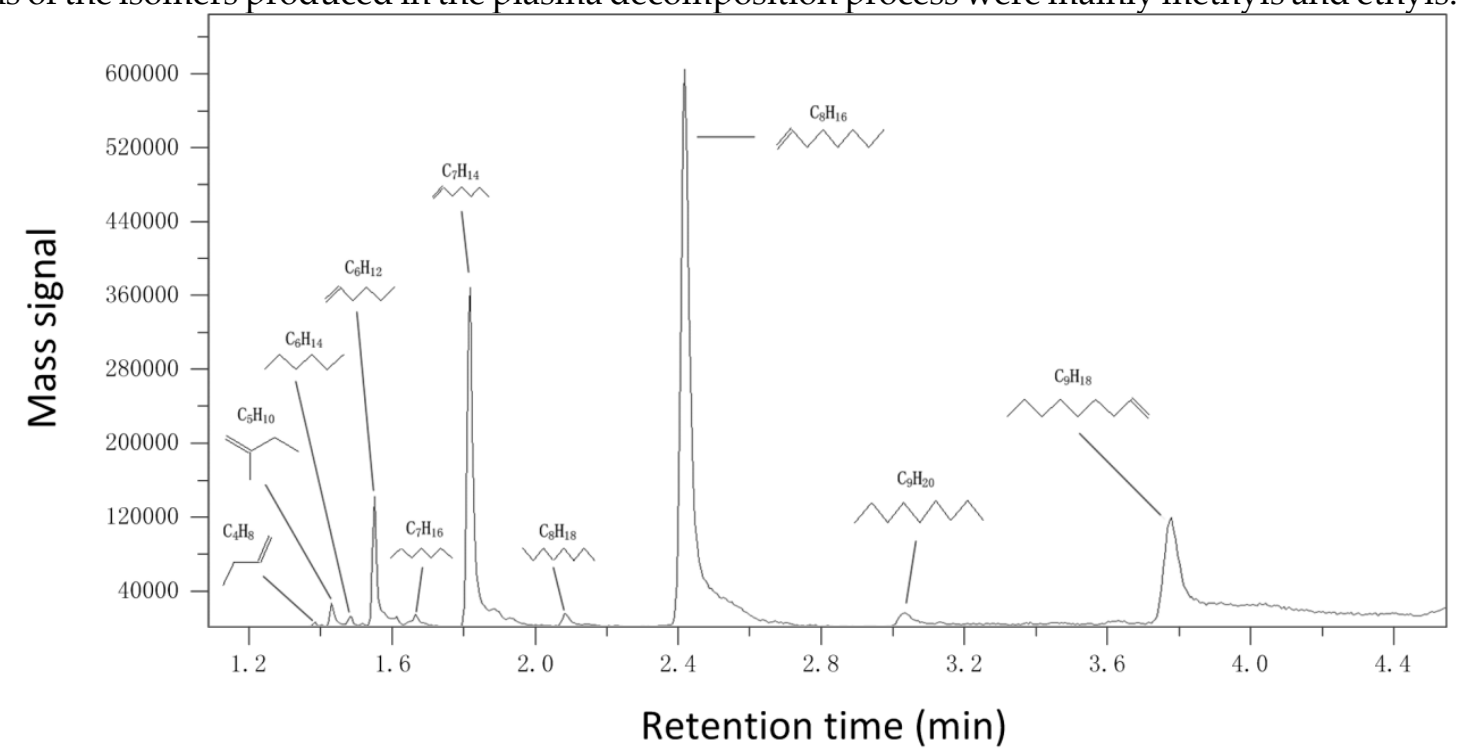




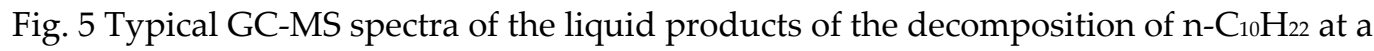
preheating temperature of $823 \mathrm{~K}$ and a discharge frequency of $5 \mathrm{kHz}$.

Table 1 Structure distribution of products under different experimental conditions.

\begin{tabular}{|c|c|c|c|c|c|c|c|c|c|c|c|c|c|c|c|c|c|}
\hline \multirow{2}{*}{$\begin{array}{c}\text { Conditions } \\
\mathrm{K} / \mathrm{kHz} \\
\end{array}$} & \multirow{2}{*}{$\begin{array}{l}\mathrm{C}_{6} \mathrm{H}_{12} \\
W\end{array}$} & \multirow{2}{*}{$\begin{array}{l}\mathrm{C}_{6} \mathrm{H}_{14} \\
\mathrm{~W}\end{array}$} & \multirow{2}{*}{$\begin{array}{l}\mathrm{C}_{7} \mathrm{H}_{14} \\
M \\
M\end{array}$} & \multicolumn{2}{|c|}{$\mathrm{C}_{7} \mathrm{H}_{16}$} & \multicolumn{2}{|c|}{$\mathrm{C}_{8} \mathrm{H}_{16}$} & \multicolumn{4}{|c|}{ CsHıs } & \multirow{2}{*}{$\begin{array}{l}\mathrm{C}_{9} \mathrm{H}_{18} \\
\mathrm{MM}\end{array}$} & \multicolumn{5}{|c|}{$\mathrm{C}_{9} \mathrm{H}_{20}$} \\
\hline & & & & $M$ & $M$ & $\mathrm{MW}$ & M & MW & $m$ & MY & 5 & & $\mathrm{MM}$ & $m$ & MY & 3 & YY \\
\hline $520 / 1$ & $\sqrt{ }$ & $\checkmark$ & $\sqrt{ }$ & ᄀ & & $\checkmark$ & & $\checkmark$ & $\checkmark$ & & & $\sqrt{ }$ & $\checkmark$ & ᄀ & $\checkmark$ & & $\sqrt{ }$ \\
\hline $520 / 2$ & $\sqrt{ }$ & $\checkmark$ & $\checkmark$ & $\checkmark$ & & $\checkmark$ & & $\checkmark$ & & & & & & $\checkmark$ & $\checkmark$ & & \\
\hline $640 / 1$ & $\checkmark$ & $\checkmark$ & $\checkmark$ & $\checkmark$ & & $\checkmark$ & $\checkmark$ & & & $\checkmark$ & $\checkmark$ & $\checkmark$ & $\checkmark$ & & & $\checkmark$ & \\
\hline $640 / 2$ & $\sqrt{ }$ & $\checkmark$ & $\sqrt{ }$ & $\checkmark$ & $\sqrt{ }$ & $\checkmark$ & & $\checkmark$ & $\sqrt{ }$ & & & $\checkmark$ & $\sqrt{ }$ & $\sqrt{ }$ & & $\sqrt{ }$ & \\
\hline $750 / 1$ & $\sqrt{ }$ & & $\checkmark$ & $\sqrt{ }$ & & $\sqrt{ }$ & & $\sqrt{ }$ & & & & $\checkmark$ & $\sqrt{ }$ & & & & \\
\hline $750 / 2$ & $\sqrt{ }$ & $\sqrt{ }$ & $\sqrt{ }$ & $\checkmark$ & & $\sqrt{ }$ & & & & & & $\sqrt{ }$ & $\sqrt{ }$ & & $\sqrt{ }$ & & \\
\hline
\end{tabular}

To more clearly present the distribution of products after the plasma decomposition of $n-\mathrm{C}_{10} \mathrm{H}_{22}$, the peak areas of various isomers were added together, and the percentage of the each product in the total ion chromatogram area of all products were calculated. These results are shown in Fig. 6. At a temperature of $520 \mathrm{~K}$ and a discharge frequency of $1 \mathrm{kHz}$, decomposition was insufficient because both the temperature and discharge frequency were quite low. This led to a large percentage of the macromolecular alkane $\mathrm{C}_{9} \mathrm{H}_{20}$ (as high as $38.066 \%$ ) and a small percentage of micromolecular olefins such as $\mathrm{C}_{7} \mathrm{H}_{14}$. With an increase in temperature and discharge frequency, $\mathrm{n}-\mathrm{C}_{10} \mathrm{H}_{22}$ was further cracked. Thus, there was a sharp decrease in the percentage of $\mathrm{C}_{9} \mathrm{H}_{20}$ and an increase in the percentages $\mathrm{C}_{8} \mathrm{H}_{16}$ and $\mathrm{C}_{7} \mathrm{H}_{14}$. In particular, under $750 \mathrm{~K} / 2 \mathrm{kHz}$, the percentage of $\mathrm{C}_{8} \mathrm{H}_{16}$ was $79.042 \%$, which was almost twice as great as that under $520 \mathrm{~K} / 1 \mathrm{kHz}$. Moreover, the percentage of $\mathrm{C}_{8} \mathrm{H}_{16}$ was always highest under different experimental conditions, and this can be explained by the energies of the chemical bonds. The bond dissociation energy of $\mathrm{C}-\mathrm{C}$ in a straight-chain alkane is approximately 32.6 61.9 $\mathrm{kJ} / \mathrm{mol}$ lower than that of the $\mathrm{C}-\mathrm{H}$ bond, and the bond dissociation energy of $\mathrm{C}_{2}-\mathrm{C}_{3}$ is $4.8 \sim 8.8 \mathrm{~kJ} / \mathrm{mol}$ lower than that of the $\mathrm{C}_{1}-\mathrm{C}_{2}$ bond [25]. Moreover, the closer the $\mathrm{C}-\mathrm{C}$ bond is to the center of the molecule, the greater the bond dissociation energy for octane. Thus, it is speculated that, during the collision-induced decomposition process of $\mathrm{n}-\mathrm{C}_{10} \mathrm{H}_{22}$, the dissociation of the $\mathrm{C}_{2}-\mathrm{C}_{3}$ bond mainly contributed to the consumption of $\mathrm{n}-\mathrm{C}_{10} \mathrm{H}_{22}$ and to the production of a great number of octyls. The dissociation of the $\beta-\mathrm{C}-\mathrm{H}$ bond then led to the formation of 1-octylene. In addition, the olefins content in the cracked products exceeded the content of alkanes with the same number of $C$ atoms under high temperature and frequency as seen in Fig. 6. The present results along with Cheng's conclusions in Refs. [5-6], further verify the broad prospects of plasma decomposition in combustion under extreme conditions.

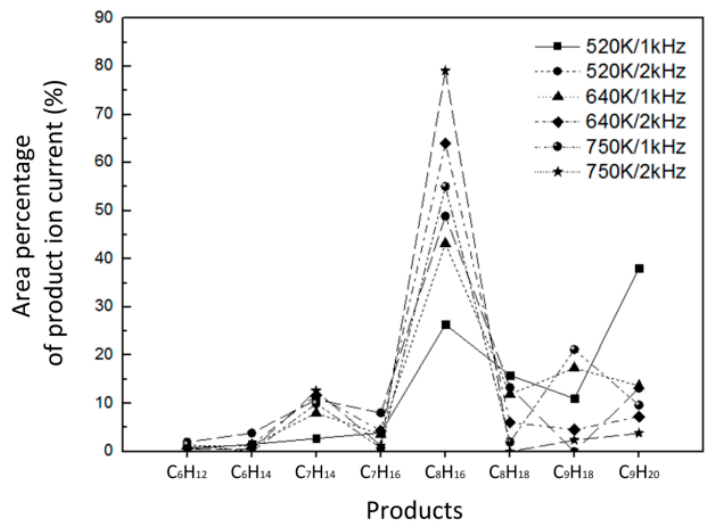

Fig. 6 Normalized percentages of various decomposition products of $n-\mathrm{C}_{10} \mathrm{H}_{20}$.

Fig. 7 (a) shows the percentages of total products, which were calculated by adding the peak area of $n-\mathrm{C}_{10} \mathrm{H}_{22}$ to the products ion current area. The current retention time was $72 \mathrm{~ms}$, and the microsecond-pulse discharge frequency was $1 \mathrm{kHz}$ or $2 \mathrm{kHz}$. Thus, $\mathrm{n}-\mathrm{C}_{10} \mathrm{H}_{22}$ underwent 72 or 144 pulses when passed through the cracker. Overall, few cracked products were produced, which only accounted for a small percentage. However, these percentages of products showed obvious regularity with the change in temperature or discharge frequency, which an increase in temperature and discharge frequency remarkably enhanced the percentages of products. For example, the total 
percentage of products at $750 \mathrm{~K} / 2 \mathrm{kHz}$ was 6 times greater than that at $520 \mathrm{~K} / 1 \mathrm{kHz}$. Fig. 7 (b) shows the percentage of olefins in the products under different experimental conditions. In combination with Fig. 7 (a), it was concluded that at higher temperature and discharge frequency, more cracked products were produced, and olefins accounted for an increasingly greater percentage of the products.

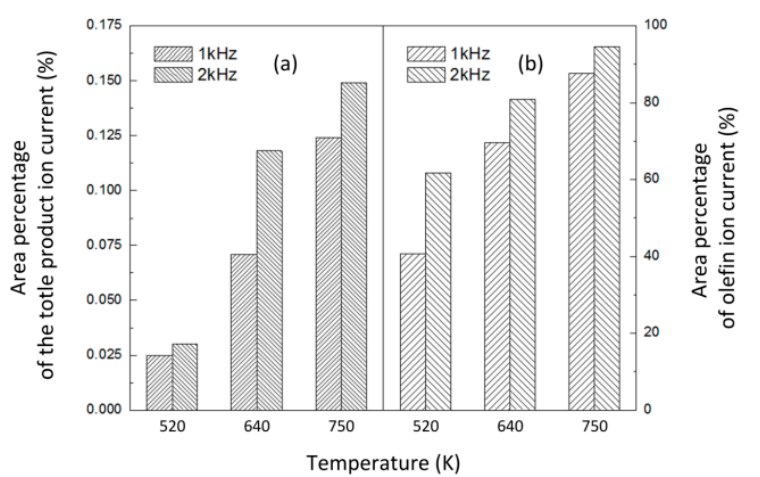

Fig. 7 Under different experimental conditions. (a) Percentages of total products. (b) Percentages of olefins in the products.

The percentages of alkanes and olefins under different conditions are compared in Fig. 8. At the same discharge frequency, as the temperature increased, the percentages of various olefins gradually increased [Fig. 8 (a) and (c)], and the percentages of various alkanes decreased correspondingly [Fig. 8 (b) and (d)]. At the same preheating temperature, an increase in the discharge frequency resulted in a decrease of the percentage of $\mathrm{C}_{9} \mathrm{H}_{18}$ and an increase of the percentages of $\mathrm{C}_{6} \mathrm{H}_{12}, \mathrm{C}_{7} \mathrm{H}_{14}$, and $\mathrm{C}_{8} \mathrm{H}_{16}$ [Fig. 8 (a) and (c)]; for alkanes, the percentages of $\mathrm{C}_{9} \mathrm{H}_{20}$ and $\mathrm{C}_{8} \mathrm{H}_{18}$ dropped, but the percentages of $\mathrm{C}_{6} \mathrm{H}_{14}$ and $\mathrm{C}_{7} \mathrm{H}_{16}$ increased [Fig. 8 (b) and (d)]. Accordingly, it was concluded that, an increase in the preheating temperature and discharge frequency caused different effects on the percentage distributions of the products. In particular, the rise of temperature widened the differences of the percentages between alkanes and olefins, while the increase of discharge frequency enhanced the selectivity of micromolecular hydrocarbon. Thus, the combination of preheating and plasma decomposition had the advantage of selectivity for small-molecular olefins.

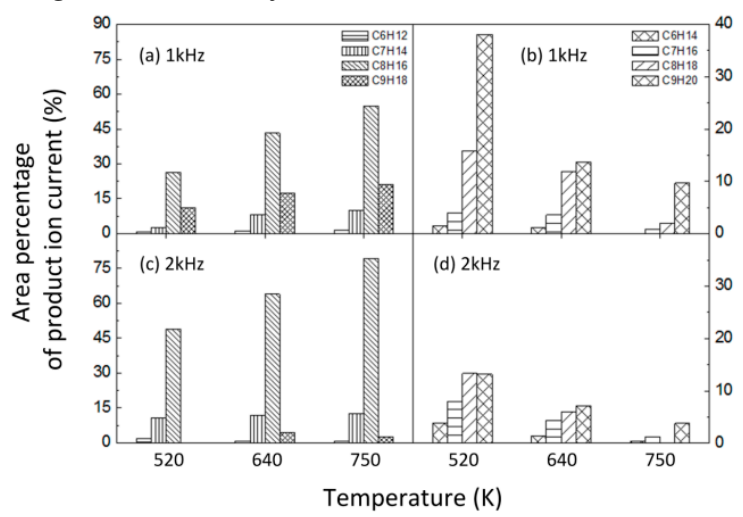

Fig. 8 Percentages of different alkanes and olefins under different experimental conditions.

To verify these conclusions, plasma decomposition tests were conducted at a preheating temperature of $823 \mathrm{~K}$ and a discharge frequency of $5 \mathrm{kHz}$. The GC-MS results of the liquid products are shown in Fig. 5. On one hand, the percentage of the cracked products was $0.241 \%$, which was $61.7 \%$ higher than the value at $750 \mathrm{~K} / 2 \mathrm{kHz}$, and the percentage of olefines in the products further increased to $96.072 \%$. On the other hand, the percentage of $\mathrm{C}_{8} \mathrm{H}_{16}$ decreased to $54.19 \%$, and the percentages of $\mathrm{C}_{7} \mathrm{H}_{14}$ and $\mathrm{C}_{6} \mathrm{H}_{12}$ increased to $20.111 \%$ and $5.93 \%$, respectively. Additionally, some micromolecular olefins, $\mathrm{C}_{5} \mathrm{H}_{10}$ and $\mathrm{C}_{4} \mathrm{H}_{8}$, were detected. At the same time, the results of the experiments showed some tendency, with strong discharge conditions, more micromolecular olefins were produced, and gradually accounted for higher percentage component in the products. 


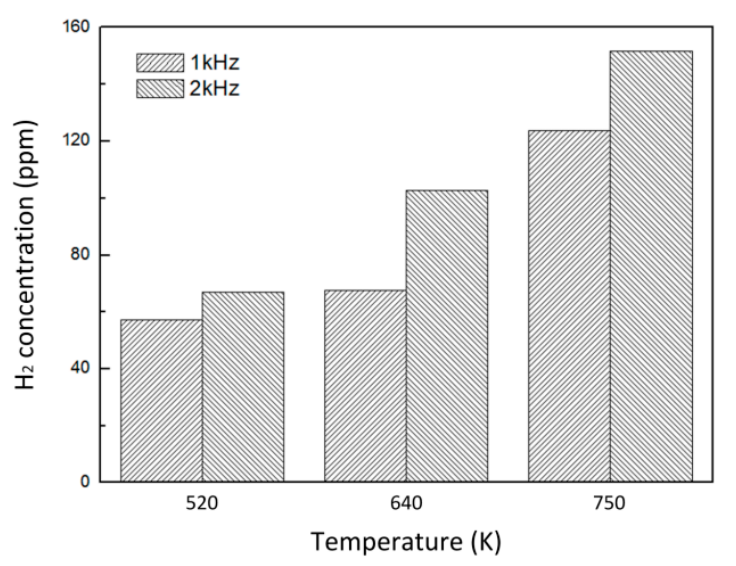

Fig. 9 Effects of preheating temperature and discharge frequency on hydrogen production.

After water-cooling, the gaseous products were collected and tested using gas chromatography (7890A). Fig. 9 shows hydrogen production under different experimental conditions, and it is easily seen that both the preheating temperature and the discharge frequency significantly affected hydrogen production. As stated above, an increase in temperature and discharge frequency led to an increase of octyl. As a result, more $\mathrm{H}$ atoms formed by the $\beta-\mathrm{C}-\mathrm{H}$ bond dissociation in octyl acted as free radials and attached to other alkyl molecules, initiating a dehydrogenation reaction and producing more hydrogen. In additional experiments, more gaseous products were detected, including $\mathrm{H}_{2}, \mathrm{CH}_{4}, \mathrm{C}_{2} \mathrm{H}_{4}$ and $\mathrm{C}_{2} \mathrm{H}_{6}$, in concentrations of $293.446 \mathrm{ppm}, 205.441 \mathrm{ppm}, 671.064 \mathrm{ppm}$, and $210.113 \mathrm{ppm}$, respectively. The production of hydrogen was nearly twice as much as that at $750 \mathrm{~K} / 2$ $\mathrm{kHz}$. Additionally, the ratio of ethylene to ethane was approximately 3.2:1. The analysis of gaseous products also verified the advantage of the combination of preheating and plasma decomposition in the selectivity of the olefins.

\section{Conclusions}

Plasma decomposition of n-decane was conducted using a parallel-plate dielectric barrier discharge cracker at different preheating temperatures $(520 \mathrm{~K}, 640 \mathrm{~K}, 750 \mathrm{~K}$, and $823 \mathrm{~K})$ and discharge frequencies $(1 \mathrm{kHz}, 2 \mathrm{kHz}$, and $5 \mathrm{kHz}$ ). The cracker was excited using a microsecond-pulse power supply, and GC and GC-MS were used to investigate the compositions of the cracked products under different experimental conditions. According to GC and GC-MS results, the direct collision between metastable-state Ar atoms and $n-\mathrm{C}_{10} \mathrm{H}_{22}$ led to the dissociation of $\mathrm{C}_{2}-\mathrm{C}_{3}$ bonds, and this greatly contributed to the consumption of $\mathrm{n}-\mathrm{C}_{10} \mathrm{H}_{22}$. An increase in the preheating temperature and discharge frequency enhanced the production of hydrogen in the cracked products and more cracked hydrocarbons were produced, in which olefins accounted for an increasingly greater percentage in the products. Under different experimental conditions, the percentage of olefins was higher than that of alkanes with the same number of $C$ atoms. Varying the preheating temperature and discharge frequency caused different effects on the distribution of cracked products. Specifically, an increase in temperature widened the ratio of olefins to alkanes; at a higher discharge frequency, micromolecular hydrocarbons were more easily produced. There was a general tendency that the percentage of micromolecular olefins increased steadily and gradually accounted for higher percentage in products.

Acknowledgments: This paper was supported by the National Natural Science Foundation of China (Nos. 91541120, 51507187, 51407197, 11472306).

Author Contributions: Yun Wu and Di Jin conceived the experiments; Feilong Song performed the experiment and analyzed the data; Min Jia, Wenen Wei and Huimin Song contributed experimental tools; Feilong Song wrote the paper.

Conflicts of Interest: The authors declare no conflict of interest. 


\section{References}

1. Dyer R, Naples A, Kaemming T, et al. Parametric testing of a unique rotating detonation engine design[C]//50th AIAA Aerospace Sciences Meeting including the New Horizons Forum and Aerospace Exposition. 2012: 121.

2. Welsh D J, King P, Schauer F, et al. RDE integration with T63 turboshaft engine components[C]//52nd Aerospace Sciences Meeting. 2014: 1316.

3. Yang $\mathrm{C}, \mathrm{Wu} \mathrm{X}, \mathrm{Ma} \mathrm{H}$, et al. Experimental research on initiation characteristics of a rotating detonation engine[J]. Experimental Thermal and Fluid Science, 2016, 71: 154-163.

4. Liu S J. Investigations on the structure, rotating mode and lasting mechanism of continuous rotating detonation wave[J]. Changsha: National University of Defense Technology, 2012.

5. Cheng Y, Hu E, Lu X, et al. Experimental and kinetic study of pentene isomers and n-pentane in laminar flames[J]. Proceedings of the Combustion Institute, 2016.

6. Cheng Y, Hu E, Deng F, et al. Experimental and kinetic comparative study on ignition characteristics of 1-pentene and n-pentane[J]. Fuel, 2016, 172: 263-272.

7. Shrestha U, Simms G, Chelliah H K. High-pressure fuel pyrolysis investigation using a microflow tube reactor[C]//53rd AIAA Aerospace Sciences Meeting. 2015: 0418.

8. Zeng M, Yuan W, Wang Y, et al. Experimental and kinetic modeling study of pyrolysis and oxidation of n-decane[J]. Combustion and Flame, 2014, 161(7): 1701-1715.

9. Li X, Shen B, Xu C. Interaction of titanium and iron oxide with ZSM-5 to tune the catalytic cracking of hydrocarbons[J]. Applied Catalysis A: General, 2010, 375(2): 222-229.

10. Marcilla A, Gómez A, Reyes-Labarta J A, et al. Kinetic study of polypropylene pyrolysis using ZSM-5 and an equilibrium fluid catalytic cracking catalyst[J]. Journal of Analytical and Applied Pyrolysis, 2003, 68: 467-480.

11. Cheekatamarla P K, Lane A M. Catalytic autothermal reforming of diesel fuel for hydrogen generation in fuel cells: II. Catalyst poisoning and characterization studies[J]. Journal of power sources, 2006, 154(1): 223-231.

12. Zhang K, Wang R, Han W, et al. Progress of heavy oil processing by plasma technology[J]. Transactions of China Electrotechnical Society, 2016, 31(24): 1-5.

13. Wang J, Li Y, Tian Z, et al. Low temperature plasma diagnostics with tunable synchrotron vacuum ultraviolet photoionization mass spectrometry[J]. Review of Scientific Instruments, 2008, 79(10): 103504.

14. Yao $S$, Weng $S$, Jin $Q$, et al. Mechanism of decane decomposition in a pulsed dielectric barrier discharge reactor[J]. IEEE Transactions on Plasma Science, 2016, 44(11): 2660-2666.

15. Prieto G, Okumoto M, Takashima K, et al. A plate-to-plate plasma reactor as a fuel processor for hydrogen-rich gas production[C]//Industry Applications Conference, 2001. Thirty-Sixth IAS Annual Meeting. Conference Record of the 2001 IEEE. IEEE, 2001, 2: 1099-1102.

16. Yu H, Ling $\mathrm{W}$, Zhao $\mathrm{M}$, et al. Reaction of dielectric barrier discharge plasma with crude oil[J]. Nuclear Fusion and Plasma Physics, 2012, 32(3): 271-277.

17. Tsolas N, Togai K, Yetter R. Flow Reactor Studies with Nanosecond Pulsed Discharges at Atmospheric Pressure and Higher[R]. PENNSYLVANIA STATE UNIV STATE COLLEGE DEPT OF MECHANICAL AND NUCLEAR ENGINEERING, 2013. 
18. Dagaut P, Reuillon M, Boettner J C, et al. Kerosene combustion at pressures up to 40 atm: Experimental study and detailed chemical kinetic modeling[C]//Symposium (International) on Combustion. Elsevier, 1994, 25(1): 919-926.

19. Dagaut P, El Bakali A, Ristori A. The combustion of kerosene: Experimental results and kinetic modelling using 1-to 3-component surrogate model fuels[J]. Fuel, 2006, 85(7): 944-956.

20. Humer S, Frassoldati A, Granata S, et al. Experimental and kinetic modeling study of combustion of JP-8, its surrogates and reference components in laminar nonpremixed flows[J]. Proceedings of the Combustion Institute, 2007, 31(1): 393-400.

21. Balamuta J, Golde M F. Quenching of metastable Ar, Kr, and Xe atoms by oxygen - containing compounds: A resonance fluorescence study of reaction products[J]. The Journal of Chemical Physics, 1982, 76(5): 2430-2440.

22. Balamuta J, Golde M F, Ho Y S. Product distributions in the reactions of excited noble - gas atoms with hydrogen - containing compounds[J]. The Journal of chemical physics, 1983, 79(6): 2822-2830.

23. Tsolas N, Togai K, Yetter R A. Non-Equilibrium Plasma-Assisted Flow Reactor Studies of Highly Diluted Reactive Mixtures[C]//53rd AIAA Aerospace Sciences Meeting. 2015: 0159.

24. Malewicki T, Brezinsky K. Experimental and modeling study on the pyrolysis and oxidation of n-decane and n-dodecane[J]. Proceedings of the Combustion Institute, 2013, 34(1): 361-368.

25. Luo Y R. Comprehensive handbook of chemical bond energies[M]. CRC press, 2007. 